\title{
Eyeblink classical conditioning and post-traumatic stress disorder - a model systems approach
}

\author{
Bernard G. Schreurs ${ }^{1,2 *}$ and Lauren B. Burhans ${ }^{1,2}$ \\ ' Blanchette Rockefeller Neurosciences Institute, West Virginia University, Morgantown, WV, USA \\ ${ }^{2}$ Department of Physiology and Pharmacology, West Virginia University, Morgantown, WV, USA
}

\section{Edited by:}

Lucien T. Thompson, University of

Texas at Dallas, USA

\section{Reviewed by:}

Stephen Daniel Berry, Miami

University, USA

John T. Green, University of Vermont USA

\section{*Correspondence:}

Bernard G. Schreurs, Blanchette Rockefeller Neurosciences Institute, 8 Medical Center Drive, Morgantown, WV 26506, USA

e-mail:bschreurs@hsc.wvu.edu
Not everyone exposed to trauma suffers flashbacks, bad dreams, numbing, fear, anxiety, sleeplessness, hyper-vigilance, hyperarousal, or an inability to cope, but those who do may suffer from post-traumatic stress disorder (PTSD). PTSD is a major physical and mental health problem for military personnel and civilians exposed to trauma. There is still debate about the incidence and prevalence of PTSD especially among the military, but for those who are diagnosed, behavioral therapy and drug treatment strategies have proven to be less than effective. A number of these treatment strategies are based on rodent fear conditioning research and are capable of treating only some of the symptoms because the extinction of fear does not deal with the various forms of hyper-vigilance and hyperarousal experienced by people with PTSD. To help address this problem, we have developed a preclinical eyeblink classical conditioning model of PTSD in which conditioning and hyperarousal can both be extinguished. We review this model and discuss findings showing that unpaired stimulus presentations can be effective in reducing levels of conditioning and hyperarousal even when unconditioned stimulus intensity is reduced to the point where it is barely capable of eliciting a response. These procedures have direct implications for the treatment of PTSD and could be implemented in a virtual reality environment.

Keywords: conditioning-specific reflex modification, explicitly unpaired, extinction, reflex modification, rabbit nictitating membrane response, virtual reality

\section{INTRODUCTION}

People exposed to trauma who suffer flashbacks, bad dreams, numbing, fear, anxiety, sleeplessness, hyper-vigilance, hyperarousal, or an inability to cope comprise the $15-25 \%$ who suffer from post-traumatic stress disorder (PTSD) (1-3). There is a crucial need to know how responding to stressful events changes as a function of trauma for patients who suffer from PTSD and particularly combat-related PTSD - a condition that can be resistant to behavioral and drug therapy $(2,4,5)$. PTSD is the most common psychiatric condition for which veterans seek services $(6,7)$. PTSD among veterans may be 3 times higher than in the general population, although it may be 30 times higher in combat veterans (8). Even these numbers may be underestimates due to underreporting of mental disorders in active duty personnel because of perceived weakness, loss of confidence, stigma, and threat to career posed by a need for mental health services $(6,9-11)$. Adding further concern are recent findings that PTSD can lead to an increased risk of dementia $(12,13)$ and PTSD symptoms can last more than 15 years (14). Despite some progress in diagnosing and treating PTSD in civilians, treating veterans is less successful $(5,15,16)$, and PTSD among veterans results in increased death $(17,18)$ including suicide $(18,19)$. It is clear every effort, including better animal modeling, needs to be made to improve our understanding and treatment of PTSD.

Researchers have developed a range of animal models of PTSD $(3,20-29)$. Although animal models cannot capture all the aspects of a human disorder, they are invaluable for developing and testing potential treatments, especially when a model expresses more than one phenotype of PTSD (30-33). However, many of the current animal models of PTSD have limitations. First, they focus on the fear associated with trauma (fear conditioning) without assessing or treating the hyperarousal caused by trauma or they focus on stress-induced hyperarousal without assessing or treating fear conditioning. Second, the majority of animal models rely on group data, and it is clear that not everyone exposed to trauma develops $\operatorname{PTSD}(2,13,30,34,35)$. In fact, depending on the population and on the type of trauma, only $5-25 \%$ of exposed people develop PTSD (1-3).

We have developed an animal model of PTSD in which conditioning and hyperarousal can both be extinguished (36). The model is based on observations that the eyeblink response becomes exaggerated as a function of classical conditioning (37-43). The exaggerated response occurs when the eliciting stimulus such as an air puff or periorbital electrical stimulation is tested by itself, and this form of hyperarousal is termed conditioningspecific reflex modification (CRM). CRM is detected by comparing responses to a range of unconditioned stimulus (US) intensities by themselves before and after classical conditioning. This phenomenon has been observed by others in rabbit eyeblink conditioning $(44,45)$ and in rat eyeblink conditioning (46). We now have strong evidence we can "treat" CRM as well as extinguish conditioned responses (CRs) to stimuli associated with the US. Importantly, high levels of CRM only occur in $15-25 \%$ of rabbits exposed to eyeblink classical conditioning 
(EBCC) - levels that are consistent with the incidence of PTSD $(2,3,35)$

\section{EYEBLINK CLASSICAL CONDITIONING EBCC IN HUMANS}

The history of human EBCC dates back to German studies beginning in 1899 and described by Woodruff-Pak and Steinmetz (47) who referenced an exhaustive bibliography of over 500 human EBCC studies from 1899 to 1985 compiled by Gormezano (48). EBCC in the United States was pioneered by Cason in 1922 using electric shock as the US (49). EBCC was then expanded upon by Hilgard in a subsequent series of studies in the 1930s with rats, dogs, monkeys, and humans which were all conducted with what has become the standard US for EBCC particularly in humans - a puff of air to the eye (50). The first documented studies of EBCC to investigate psychiatric disorders were published in the 1950s by Spence and Taylor when EBCC was assessed in subjects with anxiety (51) and those with neurosis and psychosis $(52,53)$.

The first report of EBCC in patients with PTSD was a study by Ayers and colleagues using delay conditioning in veterans (54). A number of other studies followed mostly in veterans (55-58) and one in civilians (59). The consensus of these studies is that there may be changes in EBCC as a result of PTSD but the effects are quite variable and may involve personality traits (57). These studies are reviewed in more detail in the accompanying articles from the Servatius laboratory.

\section{EBCC IN ANIMALS}

As noted above, the history of EBCC in animals began with studies using dogs in 1935, monkeys in 1936 (50), and rats in 1938 (60). Perhaps because of the strong focus on human eyelid conditioning in the intervening years (48), little if any attention was paid to EBCC in animals until the 1960s. A return to EBCC in animals may also have reflected the neurobiological limitations inherent in and the growing theoretical and methodological controversies surrounding human EBCC $(47,61,62)$. To address these methodological issues as well as provide the behavioral basis for studying learning's neural substrates, Gormezano and colleagues developed classical conditioning of a series of related skeletal responses in the rabbit centered on the eyelid and nictitating membrane (6366). These preparations were followed by the development of jaw movement conditioning, classical conditioning of an appetitive response (67), and heart rate conditioning, classical conditioning of an autonomic response $(68,69)$. In order to overcome the very limited ability to use invasive techniques in humans and pursue the growing interest in the neural substrates of learning, Thompson and colleagues began to use neural recording and lesion techniques to delineate the pathways and substrates of EBCC in the rabbit (70-72).

\section{REFLEX MODIFICATION}

Although the focus of nearly all classical conditioning experiments has been on the development of a CR (e.g., eyeblink) to the conditioned stimulus (CS, e.g., tone), some attention has also been paid to the unconditioned response (UR, e.g., eyeblink) to the US. For example, there is ample evidence that URs may be modified as a result of non-associative processes. Illustrated in the top panel of
Figure 1 is an example of a non-associative change in the eyeblink where repeated elicitation of the eyeblink indexed by measuring the nictitating membrane response (NMR) can lead to a reduction in the amplitude of the response known as habituation (73-81). In this example, a rabbit's response to a strong periorbital electrical stimulus $(2 \mathrm{~mA}, 100 \mathrm{~ms})$ decreases across four 20 -trial blocks of electrical stimulation presented at different intensities $(0.1,0.25$, $0.5,1.0$, and $2.0 \mathrm{~mA})$ and durations $(10,25,50,100 \mathrm{~ms})$. URs may

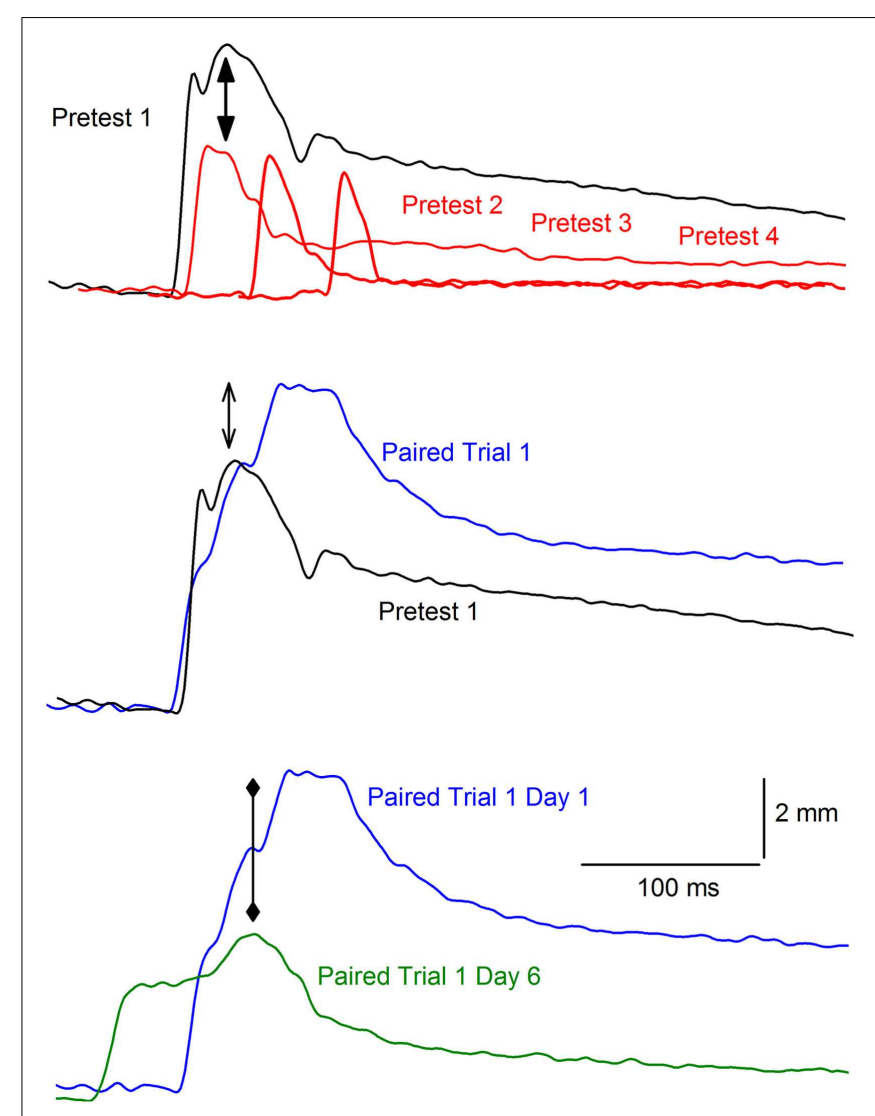

FIGURE 1 | Example of habituation and reflex modification. The top panel of the figure shows representative nictitating membrane responses (eyeblink) to a 2.0-mA, $100 \mathrm{~ms}$ periorbital electrical stimulus for an individual rabbit during the first (black, Pretest 1), second (red, Pretest 2), third (Pretest 3), and fourth (Pretest 4 ) block of pretesting to periorbital electrical stimuli of different intensities $(0.1,0.25,0.5,1.0$, and $2.0 \mathrm{~mA})$ and durations $(10,25,50,100 \mathrm{~ms})$. The onset of the responses are staggered from left to right to help illustrate the decrease in response amplitude (solid arrows) known as habituation as a function of repeated stimulus presentations across the four blocks. The middle panel shows the response on Pretest 1 (black) compared to the response to the same 2.0-mA, $100 \mathrm{~ms}$ periorbital electrical stimulus on the first paired trial (blue, Paired Trial 1) of the tone conditioned stimulus and the periorbital electrical unconditioned stimulus. The open arrows indicate the increase in the amplitude of the response known as reflex facilitation on the paired trial. The bottom panel depicts the response on the first paired trial of the tone conditioned response and the periorbital electrical unconditioned stimulus on the first day (blue, Paired Trial 1 Day 1) compared to the first paired trial on the sixth and last day (green, Paired Trial 1 Day 6). The diamond arrowheads indicate the decrease in the amplitude of the response on the later paired trial when a conditioned response is present (earlier response onset). This decrease in amplitude is known as conditioned diminution. 
also be enhanced or undergo sensitization; that is, a response to a weak stimulus will become larger if it is elicited after a series of stronger stimulations (82). Although non-associative, sensitization can also occur during pairings of the CS and US and can be estimated on the basis of unpaired presentations of these two stimuli (83). A CS may facilitate the rabbit NMR the first time the tone and air puff (or periorbital electrical stimulation) are presented together (that is, before any association could have formed between the two stimuli). Depicted in the middle panel of Figure 1 is an example of an eyeblink that increased in size in the presence of a tone CS - a phenomenon known as reflex modification, in this case reflex facilitation (84-96).

Unconditioned responses may also be modified as a result of associative processes and there is substantial evidence that a UR can be modified as a function of CS-US pairings. For example, the presence of a CS may decrease the size of the UR after repeated pairings have resulted in the formation of an association. This is a phenomenon known as conditioned diminution $(85,89)$. The bottom panel of Figure 1 shows an example of conditioned diminution where there is a decrease in the amplitude of the eyeblink UR from the first paired trial where there is no CR to a later paired trial where there is a CR (indicated by the earlier onset latency compared to the first trial on which only a UR is present).

In all of these aforementioned studies, the focus has been on changes in the UR that are attributable to the CS. Consequently, dependent variable measures, such as amplitude of the response, have been assessed in the presence of the CS as in the case of the bottom panel of Figure 1. Our original studies were influenced by the hypothesis that classical conditioning alters not only CS processing but also alters US processing. This hypothesis is consistent with a local interaction model of learning and memory in which CS and US inputs interact at a number of local dendritic sites distributed across a neuronal array $(97,98)$. It is from this background that we first observed the changes in the UR that has come to be termed CRM (37). By way of contrast to earlier studies where the UR was assessed in the presence of the $\mathrm{CS}$, the experiments reviewed here focus on the effects of conditioning on responding to the US in the absence of the CS and, hence, examined conditioning-specific effects that are intrinsic to US processing and UR production.

\section{CONDITIONING-SPECIFIC REFLEX MODIFICATION THE BASIC PHENOMENON}

Figure 2 shows an example of CRM in which representative NMRs to a $0.5-\mathrm{mA}$ periorbital electrical stimulus are shown in a rabbit before (Pretest), 1 day after (Post Test 1), and 1 month (Post Test 2) after 6 days of EBCC (Paired). The responses show clear increases in amplitude, area, and peak latency compared to the responses in a control rabbit after 6 days of explicitly unpaired presentations of the tone CS and periorbital electrical stimulation US (Unpaired). Thus, CRM occurs following EBCC and persists for a month but does not occur following explicitly unpaired stimulus presentations - the optimal control condition for assessing non-associative contributors to responding (83). CRM is detected by comparing responses to a range of US intensities presented by themselves before and after classical conditioning and has been observed by others following EBCC in rabbits $(44,45)$ and rats $(46)$. CRM is

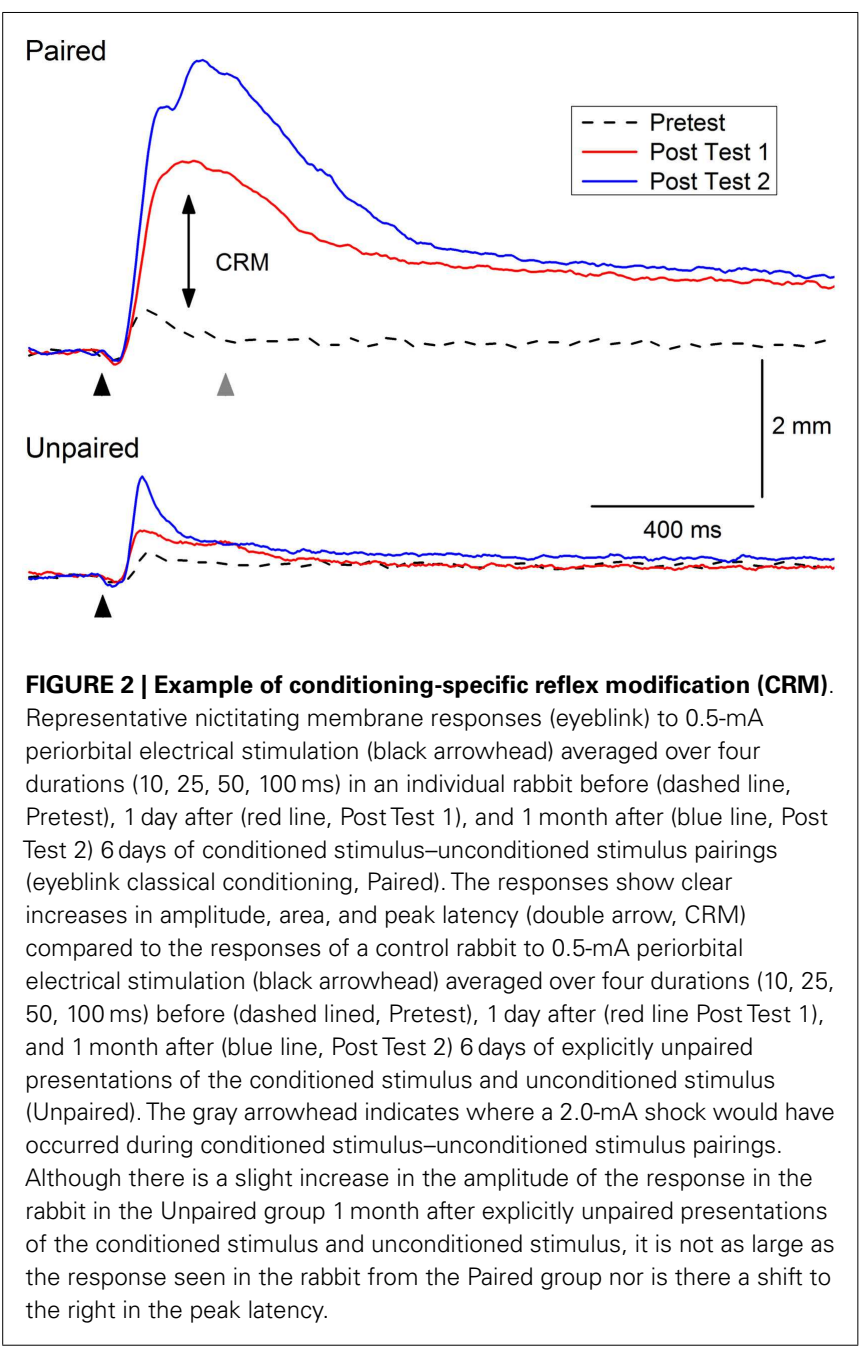

not idiosyncratic to EBCC because we have also found CRM of heart rate as a result of heart rate classical conditioning (42, 99, 100). Thus, the effect appears to exist in at least two species and in both the autonomic and the skeletal response systems. Given the subject of the present focus topic, this review will be limited to changes in the rabbit unconditioned NMR that occur as the result of EBCC because CRM of HR is obtained at conditioning parameters (i.e., long interstimulus intervals) that do not normally support EBCC. The NMR serves as a convenient index of the eyeblink as it is a component of the defensive response system consisting of closure of the upper eyelid, retraction of the eyeball, and sweep of the nictitating membrane which are very highly correlated $(63,65,101)$.

\section{BEHAVIORAL LAWS}

Rabbit EBCC has yielded a large number of behavioral "laws" that have been enumerated and detailed elsewhere $(63,66,69,102,103)$. Chief among these "laws" is the relationship between the strength and rate of EBCC and a number of parameters including CS and US intensity and duration, interstimulus interval, and number of stimulus pairings (66). In a series of experiments reviewed previously $(40,42)$, we have found that CRM is also a function of a 
number of parameters including the nature (air puff and periorbital electrical stimulation) and intensity of the US $(39,104)$, the interstimulus interval (105), and the number of pairings $(37,38)$.

\section{STIMULUS GENERALIZATION}

Another important phenomenon in rabbit EBCC that has been observed in other species and behavioral paradigms is generalization - responding to stimuli similar to the stimulus used during EBCC (106-108). CRM by its very nature is generalization along the intensity dimension of the US for both electrical stimulation and air puff (39). Due to a ceiling effect for the highest intensities of periorbital electrical stimulation, the strongest levels of CRM are detected below the training intensity (37-39). This is not the case for the weaker stimulation afforded by air puff where CRM occurs at high as well as moderate stimulus intensities (39). We have found that CRM can generalize from periorbital electrical stimulation to air puff but does not generalize from air puff to periorbital shock which seems to reflect the need for an intense US to support CRM (39) making it relevant for modeling PTSD.

\section{CONTEXT}

Previous experiments suggest that CRM obeys behavioral laws similar to those of classical conditioning and, like classical conditioning, CRM is sensitive to a shift in context (41). In a series of experiments the auditory, olfactory, tactile, and visual properties of the context in which rabbits were given EBCC and CRM testing were manipulated to determine the effects of context on the level of CRM. An initial experiment demonstrated that when CRM was tested in a novel context, CRM levels were as strong as when testing occurred in the familiar, EBCC training context. To factor out differences in the amount of exposure to the different contexts that may have explained the results of the first experiment, exposure to all contexts was equated in a second experiment. The results showed that there was less CRM when testing took place in a context that was equally familiar but different from the EBCC training context. A context-dependent reduction in responding during EBCC has been demonstrated in rabbits that showed a drop in conditioned responding of $50 \%$ when given pairings in a different context where the visual, tactile, and olfactory characteristics had been altered from the original training context (109). The reduction in responding as a result of a context shift during rabbit EBCC has been reported in other learning paradigms including fear conditioning $(110,111)$, taste aversion learning (112), and conditioned suppression (113). Consistent with this context shift effect, our context experiments show that if exposure to the contexts is equated (111), CRM can be significantly reduced, but not eliminated, by a shift in the context from training to testing.

\section{RESILIENCE AND SUSCEPTIBILITY}

Examination of individual subject data across CRM studies revealed CRM is not an all-or-none phenomenon with considerable between-subject variability in the presence and degree of CRM. Although some CRM occurs in over $50 \%$ of rabbits, high levels of CRM (one standard deviation above mean percent change) only occur in 15-25\% of rabbits even though all reach conditioning levels in excess of $85 \%$ CRs. Figure 3 shows an example of the extremes in responding by two different rabbits to the

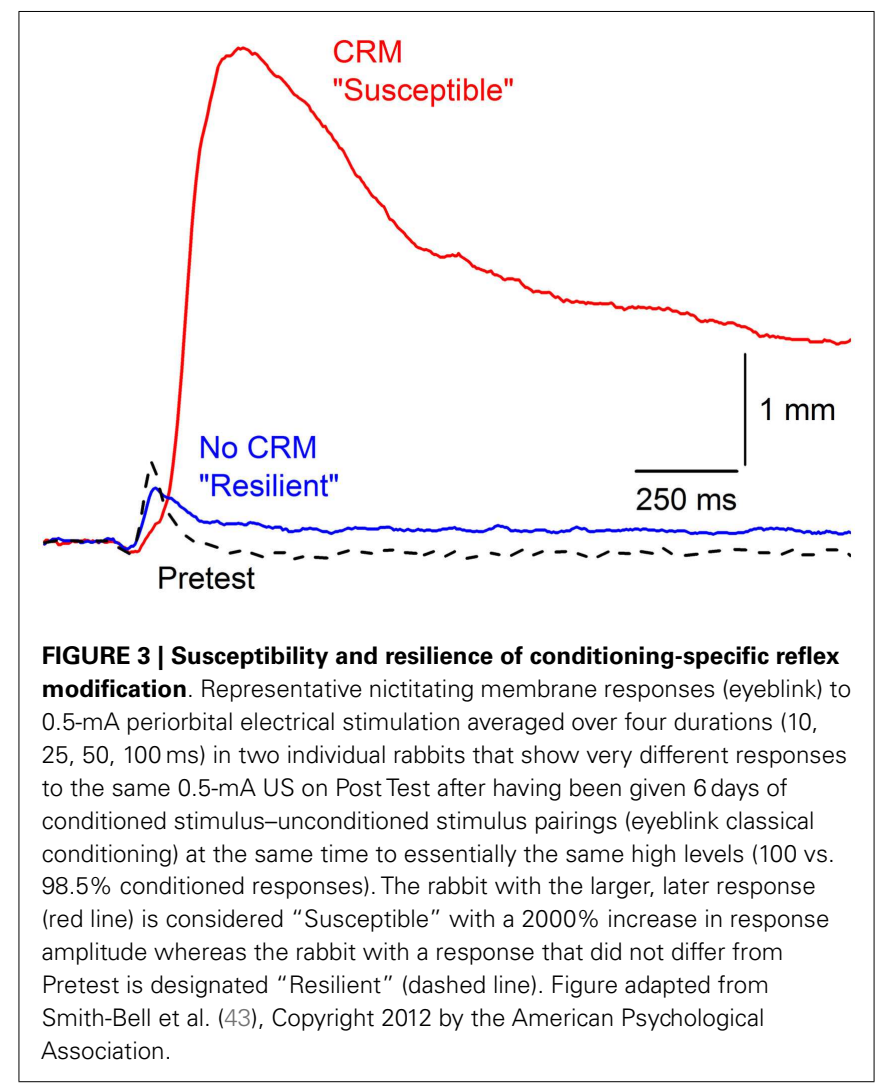

same 0.5-mA periorbital electrical stimulus. Despite high, almost identical levels of EBCC ( 100 vs. $98.5 \%$ CRs), these two subjects show profound differences in their responses to the periorbital electrical stimulus on Post Test. The first subject shows particularly strong CRM and would be considered "susceptible" whereas the second subject shows no CRM at all and would be considered "resilient." In 135 subjects trained with our standard EBCC paradigm consisting of 80 daily presentations of a $400-\mathrm{ms}, 82-\mathrm{dB}$, $1,000 \mathrm{~Hz}$ tone CS that coterminates with a $100-\mathrm{ms}, 2.0-\mathrm{mA}, 60-\mathrm{Hz}$ periorbital electrical stimulus, we found the strongest predictor of CRM (indexed by an increase in response magnitude and area) was short CR onset latency (43). We also found that during periorbital electrical stimulation on Pretest, the strongest predictor of subsequent CRM was response onset and peak latency - the faster the rabbit's response, the more likely it was to develop CRM. Therefore, the speed with which a rabbit responds to the CS during training and to the periorbital electrical stimulus during pretest are good predictors of CRM and are indices of susceptibility. This would correspond to differences in reaction time in PTSD - something that is not often observed (114-116) but has been reported (117).

\section{INCUBATION}

The symptoms of PTSD do not always occur immediately after trauma and can become more pronounced over time. A delay in the onset of symptoms by as much as 6 months has been incorporated into previous diagnostic criteria of PTSD $(118,119)$, but there is now debate about whether delayed-onset PTSD actually exists in either veterans or civilians with evidence for both points of 
view (118-124). In our animal model of PTSD symptoms, rabbits do not show a delay in onset of CRM, but there is a window during which incubation exacerbates CRM. The results are consistent with clinical data in which exacerbation or reactivation of prior symptoms accounts for $38.3 \%$ of military cases of PTSD and $15.3 \%$ of civilian cases $(120,125)$. In one set of experiments, we have observed the exacerbation of symptoms as a function of a period of incubation (126). CRM typically requires at least 3 days of EBCC when levels of conditioning reach or exceed $85 \%$ CRs $(37,39)$. We carried out an experiment (Figure 4) in which rabbits were given $\mathrm{EBCC}$ for just 1 day resulting in mean conditioning levels of only $45 \%$ CRs, and saw little evidence of CRM when tested the next day. However, if left in their home cages for 6 days, there was a significant amount of CRM which persisted for a week after testing (126). The incubation effect was not strong following 10 days in the home cage and did not persist. These data suggest there may be no delay in CRM onset but there is a window for incubation to exacerbate CRM.

\section{RESPONSE GENERALIZATION}

One of the most interesting aspects of our initial CRM experiments was the observation that, in individual subjects, responses to weak periorbital electrical stimulus intensities appeared to have a significantly different topography after EBCC than they do before EBCC and that the topography was reminiscent of the $\mathrm{CR}(37,40)$. This observation was even more clearly articulated by Gruart and Yeo (44) when they first reported changes in the rabbit eyelid UR

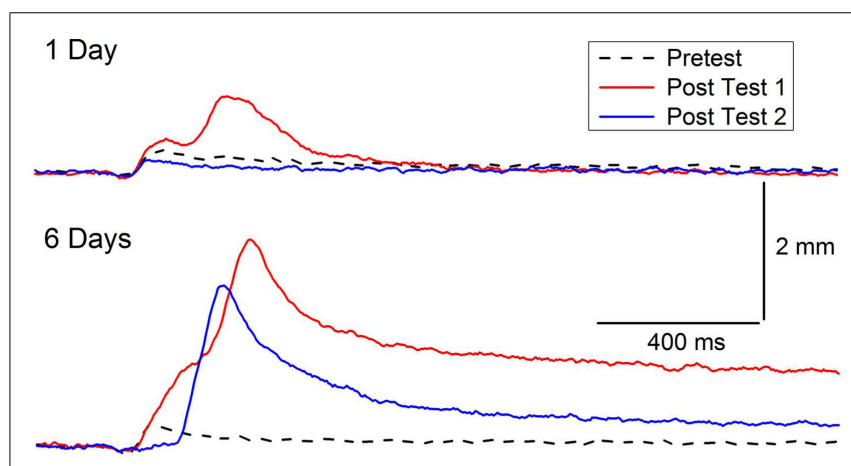

10 Days

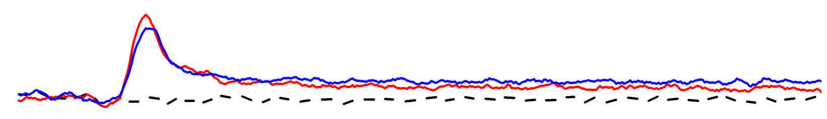

FIGURE 4 | Incubation of conditioning-specific reflex modification. Representative nictitating membrane responses (eyeblink) to a $0.25-\mathrm{mA}$ periorbital electrical stimulus averaged over four durations $(10,25,50$, $100 \mathrm{~ms}$ ) in individual rabbits before (dashed line) and after 1,6 , or 10 days of incubation in the home cage (red line) following a single session of conditioned stimulus-unconditioned stimulus pairings (eyeblink classical conditioning) which supported a level of only $45 \%$ conditioned responses. The blue lines depict nictitating membrane responses to $0.25-\mathrm{mA}$ periorbital electrical stimulation 7 days (of incubation) after Post Test 1. Although there is some suggestion of conditioning-specific reflex modification after 1 and 10 days of incubation, there was very clear and strong conditioning-specific reflex modification that occurred after 6 days of incubation and persisted a week later. Figure adapted from Schreurs et al. (126), used with permission from Elsevier. following EBCC. The marked alteration in response topography is somewhat lost in the averaging that takes place when presenting group data especially when, as noted above, not all rabbits show CRM. Figure 5 shows the strong similarity between a CR that occurs during EBCC and a UR to periorbital stimulation by itself assessed after EBCC compared to an UR assessed before EBCC. These early observations lead to the hypothesis that CRM is a CR that generalized from the CS-US pairings to the US itself $(40,44)$. A series of experiments were conducted to test this hypothesis by altering the topography of the CR by presenting two shocks during CS pairings or by presenting CS-US pairings with two different interstimulus intervals (38). The results provided evidence both for and against the hypothesis so a final experiment was designed to eliminate CRs by presenting the CS by itself during extinction (38). If the exaggerated responses to the US after EBCC (CRM) were generalized CRs, it was reasoned that eliminating the CRs should eliminate CRM. The results of this experiment were more conclusive. Despite reducing CRs to essentially baseline levels of less than $10 \%$ by presenting the CS by itself, Figure 6 shows CRM remained virtually intact. A number of control groups actually proved to be even more instructive. First, presentations of the US by itself completely eliminated CRM as shown in Figure 6 but left CRs relatively intact. Thus, the extinction of CRs left strong levels of CRM and the extinction of CRM left strong levels of conditioned responding. Second, combining presentations of the CS and the US in an explicitly unpaired manner resulted in elimination of

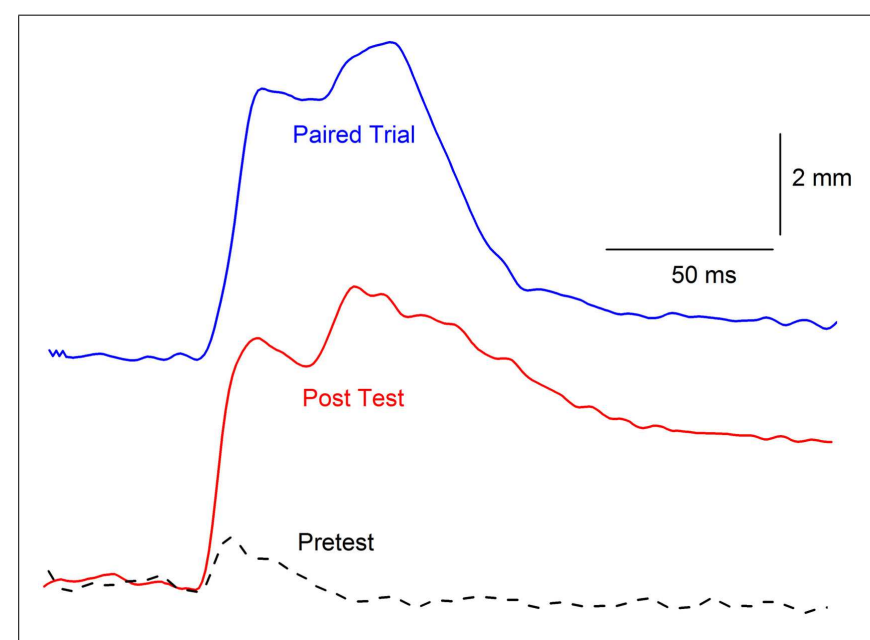

FIGURE 5 | Topographical similarity between a conditioned response and conditioning-specific reflex modification. Representative nictitating membrane responses (eyeblinks) in the same rabbit to a tone paired with shock during the third day of conditioned stimulus-unconditioned stimulus pairings (eyeblink classical conditioning, blue line, Paired Trial) and 0.5-mA periorbital electrical stimulation presented by itself before (dashed line, Pretest), and after (red line, Post Test) 6 days of conditioned

stimulus-unconditioned stimulus pairings. The response after eyeblink classical conditioning shows a strong similarity in response amplitude, peak latency, and overall topography compared to the response before eyeblink classical conditioning. The responses are shifted in time so that their onsets coincide even though the response on the paired trial is to the conditioned stimulus that overlaps with the periorbital electrical stimulus and the responses on the Pretest and Post Test trial are to 0.5-mA periorbital electrical stimulation by itself. 


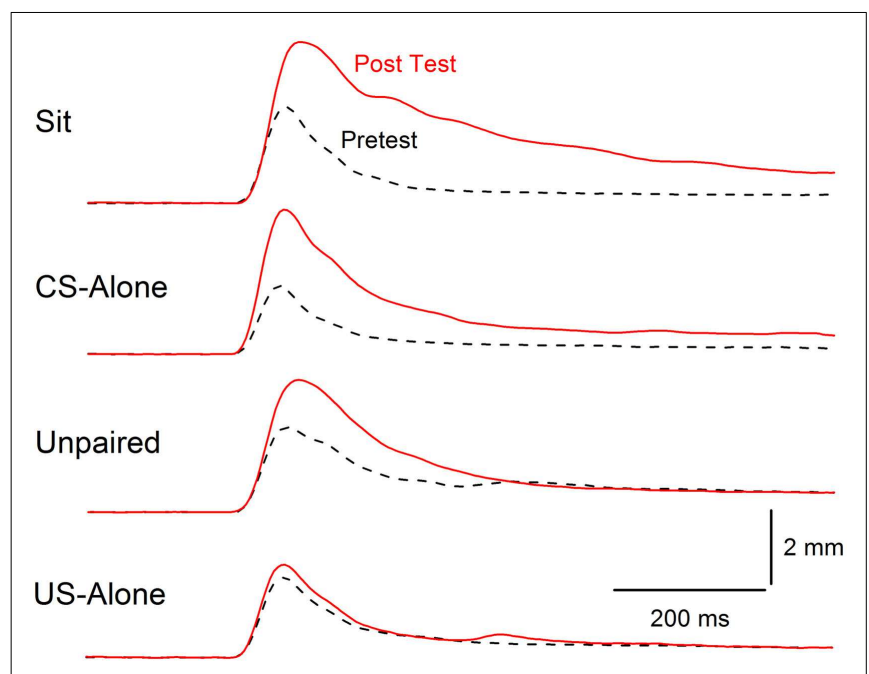

FIGURE 6 | Extinction of conditioning-specific reflex modification. Averaged nictitating membrane responses (eyeblink) to a periorbital electrical stimulus of $1.0 \mathrm{~mA}$ averaged over four durations $(10,25,50$, $100 \mathrm{~ms}$ ) for four groups of rabbits before 6 days of conditioned stimulus-unconditioned stimulus pairings (eyeblink classical conditioning) (dashed lines, Pretest) and 6 days after (red line, Post Test) either exposure to the training chamber with no further stimulus presentations (Sit), presentations of the conditioned stimulus alone (CS-alone), explicitly unpaired presentations of the conditioned stimulus and unconditioned stimulus (Unpaired), or presentations of the unconditioned stimulus alone (US-alone). The level of conditioning-specific reflex modification (CRM) was highest in the Sit group, followed by the CS-alone group, and the Unpaired group with virtually no CRM in the US-alone group. Although there was residual CRM in the Unpaired group, rabbits in this group showed no responding to the conditioned stimulus unlike rabbits in the Paired and US-alone groups suggesting that only unpaired presentations of the conditioned stimulus and unconditioned stimulus were able to significantly reduce $\mathrm{CRM}$ as well as eliminate conditioned responses to the conditioned stimulus. Figure adapted from Schreurs et al. (38), in the public domain.

CRs and a reduction in the level of CRM (Figure 6). It was these experiments that led to a further exploration of treatments that eliminate both CRs and CRM as a possible treatment strategy for PTSD.

\section{EXTINCTION OF CRM}

There is a significant body of evidence from both clinical and basic research that repeated presentation of feared stimuli does not prevent fear from returning - a phenomenon referred to as "relapse" $(127,128)$. Nevertheless, fear extinction is a cornerstone of many approaches to the treatment of PTSD $(3,28,129-137)$. However, the renewal of fear or relapse may be "thwarted" by unpaired presentations of both the feared stimulus and the event producing the fear $(38,138-140)$. Experiments drawn from a large number of different conditioning paradigms including human and rabbit EBCC (36, 39, 141-144), as well as conditioned barpress suppression in rats $(138,139)$, and human discriminative fear conditioning (140) show unpaired presentations of the CS and US produce extinction of a CR. In the human discriminative fear study, Vervleit and coworkers found that compared to normal extinction, only unpaired extinction prevented renewal of fear responses in people trained to discriminate one of two pictures paired with shock (140).

In rabbit experiments designed to extinguish EBCC, comparable extinction of responding to the CS occurs following CS-alone or unpaired CS and US presentations (38). However, as noted above and shown in Figure 6, unpaired presentations were able to extinguish CRM better than CS-alone presentations (38). The ability of unpaired presentations to diminish both CRs and exaggerated URs (i.e., CRM) suggests it may be relevant for treating both the conditioned fear and hyperarousal symptoms of PTSD $(41,42,104)$. However, no matter how effective unpaired extinction might be in extinguishing fear and hyperarousal in animal models, it would be ethically unacceptable for treating PTSD because the US intensity used in unpaired extinction has always been the same as that used to induce classical conditioning (36, $39,138-144)$. The repeated presentation of a traumatic event responsible for PTSD in order to treat it is untenable.

\section{UNPAIRED EXTINCTION THAT IS CLINICALLY RELEVANT}

To address concerns about using a traumatic stimulus during unpaired extinction and make an unpaired extinction procedure more clinically relevant, rabbit EBCC experiments were conducted in which unpaired extinction sessions employed periorbital electrical stimulation of reduced intensity that was presented for different numbers of days (36). Specifically, rabbits received US testing (Pretest), EBCC, another session of US testing to determine the size of CRM (Post Test 1), and then 1,3, or 6 days of unpaired CS and US presentations with a weak $(0.25 \mathrm{~mA})$, moderate $(1.0 \mathrm{~mA})$, or strong $(2.0 \mathrm{~mA})$ US followed by a final session of US testing to determine the effect of unpaired presentations on CRM (Post Test 2). The results revealed extinction of both CRs and CRM was a function of the US intensity used during unpaired stimulus presentations and the number of days of those unpaired stimulus presentations (36). The levels of CRs declined from $95 \%$ to less than $20 \%$ within 3 days of unpaired stimulus presentations. Figure 7 shows CRs during acquisition and 1, 3, or 6 days of unpaired extinction in which the US intensity was eight times weaker $(0.25 \mathrm{~mA})$ than the intensity used during pairings $(2.0 \mathrm{~mA})$. Figure 8 depicts sample responses from different rabbits before and after EBCC (Pretest and Post Test 1, respectively) and again after unpaired stimulus presentations (Post Test 2) with a $0.25-\mathrm{mA}$ US that were delivered for either one, three, or six daily sessions (days). The sample responses in the middle and right illustrate that after as few as three sessions of unpaired presentations with a weak US, any CRM seen after EBCC (red lines) was largely eliminated (blue lines). In contrast, the sample responses on the left show clearly that CRM was actually enhanced after a single session of unpaired presentations with a weak US. Taken together, these data suggest that both CRs and CRM seemed to be diminished, if not eliminated, most effectively with at least 3 days of mild US presentations but one session of stimulus presentations actually appears to exacerbate responding. Of note, and of particular clinical relevance, was the finding that extinction of CRs and CRM occurred even though the weak US produced relatively low levels of responding (rabbits blinked to the weak US on less than $25 \%$ of occasions). Analysis of rabbit heart rate during these sessions indicated that this weak US did not produce any 


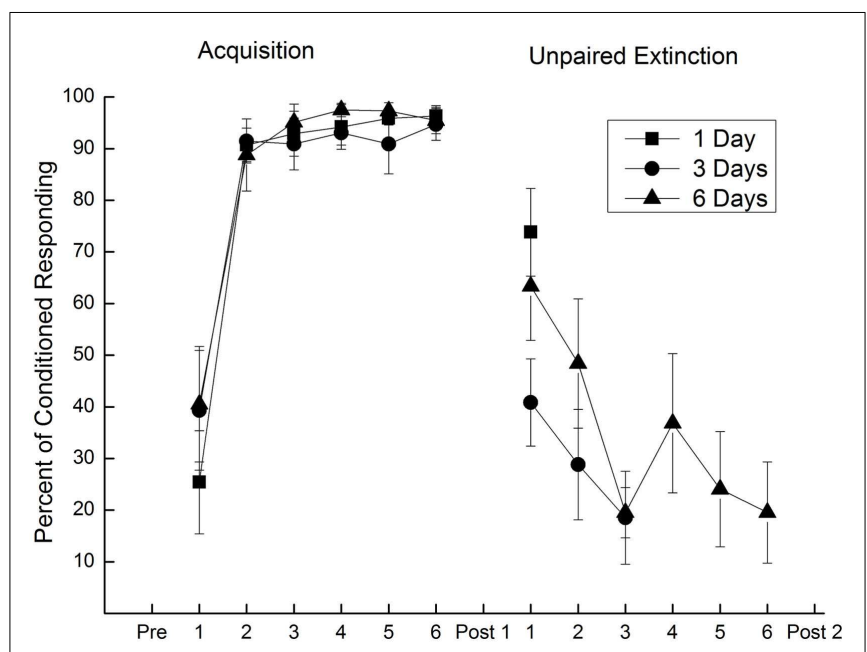

FIGURE 7 | Extinction of conditioned responding with unpaired presentations of a conditioned stimulus and weak unconditioned stimulus. Mean $( \pm$ SEM) conditioned responses to the conditioned stimulus during 6 days of pairings of a conditioned stimulus and a 2.0-mA unconditioned stimulus (Acquisition) and during one (square), three (circle), or six (triangle) subsequent days of unpaired conditioned stimulus-unconditioned stimulus presentations (Unpaired Extinction) with a 0.25-mA unconditioned stimulus. Conditioned responding increased to asymptotic levels of $95 \%$ during Acquisition and fell to less than $20 \%$ following 3 days of unpaired presentations (Unpaired Extinction). Figure adapted from Schreurs et al. (36), used with permission from Elsevier.

change in heart rate, suggesting it was not unduly stressful (36). One important implication of these data is that treatment must not be brief because brief treatment using unpaired stimulus presentations may not just be ineffectual; it may actually heighten the symptoms of PTSD.

\section{VIRTUAL REALITY}

If weakened versions of the initiating trauma are to be used as part of PTSD therapy, there would be very few such events that could or even should be repeated or recreated. The advent of credible virtual reality (VR) environments that have been developed to treat PTSD provide a feasible way around this stricture (145-151). Given the unpaired extinction data reviewed above, one could imagine a treatment situation in which a PTSD patient could be asked to describe a specific trigger or set of triggers for unwanted memories (150) and present the trigger(s) in an unpaired manner with a weakened version of an aversive event. A weakened but still stressful version of an explosion might be strongly shaking a driver's seat in a virtual Humvee which is part of a VR scenario in which the sights and sounds of combat are also presented (149-151). The VR environment could be programed to present these events in a separate, unpaired manner and the prediction would be that, with a number of repetitions over more than one session, PTSD symptoms would abate. For example, the sights, sounds of a previously traumatic context could be presented, and then the goggles and headphones would go blank and silent for a period of no stimulation which would then be followed by the driver's seat being strongly shaken. The sequence of these series of events would be randomized so that they would never occur together to reflect the explicitly unpaired procedure (83). Importantly, given that CRM has been shown to generalize from stressful periorbital electrical stimulation to what would be considered less stressful air puffs, the weakened versions of stressful events used in an unpaired extinction procedure may not need to involve the traumatic event. Psychophysiological indices including heart rate, skin conductance, respiration, and cortisol levels could be used to assess stress levels and titrate the intensity of the stimulation.

\section{METHODOLOGICAL ADDENDUM \\ STIMULUS DELIVERY AND RESPONSE MEASUREMENT}

The experiments described in this review require precise control and calibration of stimulus parameters particularly intensity and timing of the US. This is relatively straightforward for periorbital electrical stimulation through the use of programmable shock delivery equipment and the use of digital computer control. On the other hand, the delivery of air puff requires more elaborate equipment and techniques including a digitally controlled, programmable pressure regulator and an accurate digital manometer to ensure that the intensity of the air puff reflects the air striking the cornea and not the pressure at the source. Response detection is also of importance especially if response characteristics such as latency, amplitude, and area are to be determined in addition to simply registering if a response occurs or not. As a result, transduction and recording of the eyeblink response becomes important. Researchers may wish to consider the advantages and disadvantages of remotely sensing versus directly measuring the closure of the eyelid using mechanical coupling. For example, infrared reflectance measures may not be capable of completely quantifying the peak latency of a response whereas mechanical couple may produce drag that subtly alters the latency and amplitude of a response (152). EMG recording of the orbicularis oculi muscle may have advantages but the electrical noise induced by periorbital electrical stimulation as well as time constants of integration affecting onset latency and difficulty in determining units of response amplitude present limitations in quantifying the UR.

\section{DATA ANALYSIS}

Even if the UR is transduced accurately, questions remain about the analysis of data, particularly when responses are at the limits of detectability as the result of very weak stimulation. By convention and due, in part, to the limits of analog instrumentation, an NMR or eyeblink response has been defined as movement of at least $0.5 \mathrm{~mm}(61,66,153,154)$. How then is a change in response amplitude and latency from pretest to post test determined if there is no response on pretest but a significant response on post test as often occurs after EBCC? The main issue has always been what to do about the lack of a response on pretest or post test. We have addressed this in several ways including analyzing individual subject data only for US parameters at which responses occurred (37-39, 104), averaging topographies across subjects and analyzing for changes in skew and kurtosis $(41,155)$, and calculating percent change where a response on a test was considered to be a $100 \%$ change if there was no response on the other test (43). Most recently, two additional measures, magnitude of the response and magnitude of the response area, have been calculated to overcome the limitations of empty data cells on pretest or post test resulting 


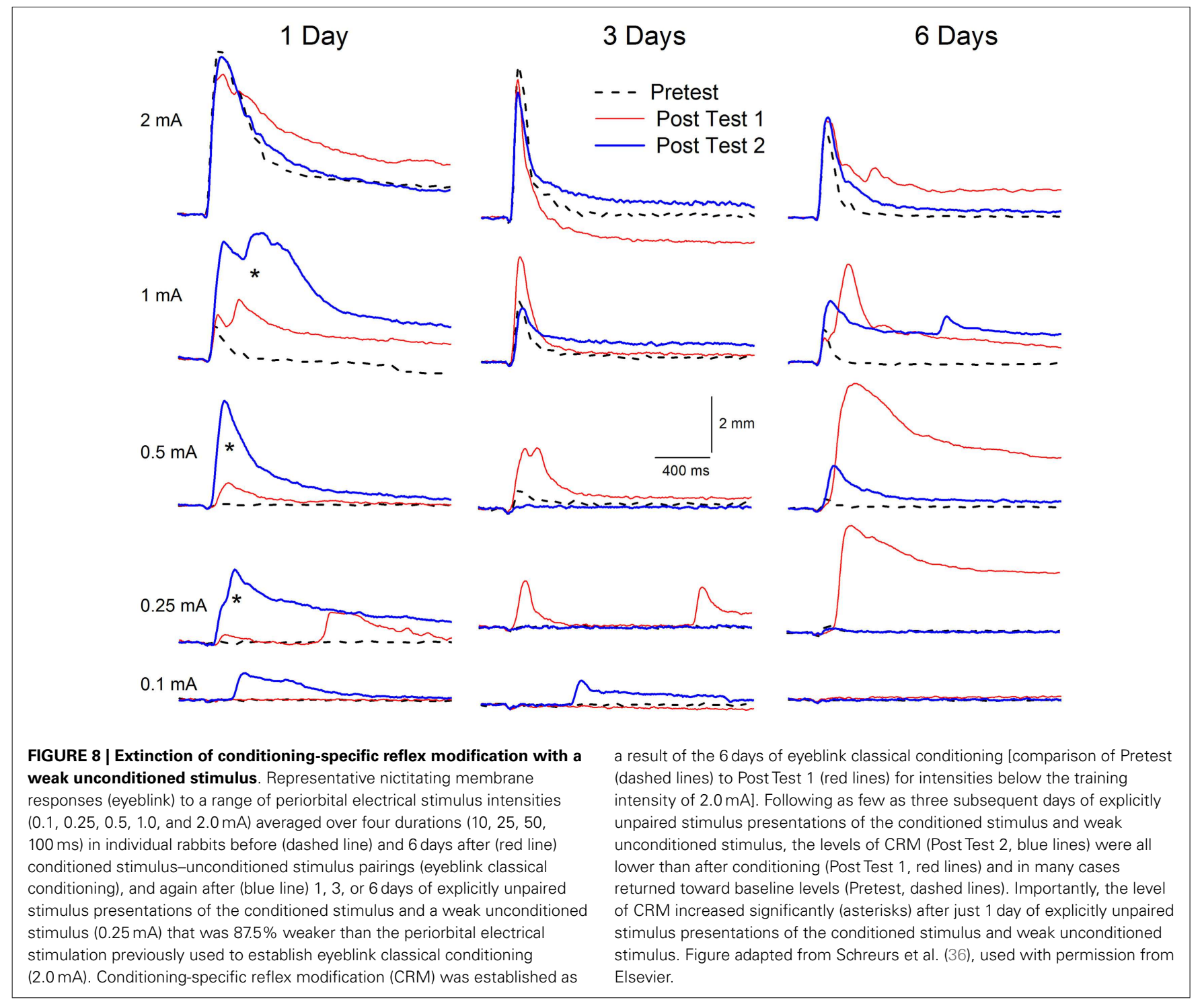

from subthreshold URs, particularly at lower US intensities and durations $(36,43,126)$. Magnitude of the response and magnitude of the response area have included the amplitudes and areas of all nictitating membrane movements above baseline and provide the most procedurally neutral estimates of responding (154).

\section{CONDITIONED RESPONSE DEFINITION}

Another issue in data analysis turns upon the practice of categorizing responses as CRs if they are "adaptively timed," a term based on the onset latency of responses (this is probably wrong anyway because one should be looking at the latency of the peak to coincide with US delivery but that would require CS-alone test trials that are un-confounded with the UR to the US which many experiments do not include). The concept of adaptively timed responses is based on the notion that CRs lessen or even avoid the aversiveness of the US when the maximum closure of the eyelid coincides with the occurrence of the US. This adaptive response may therefore be argued as being reinforcing, adding an instrumental component to CRs also known as the "law of effect" (156-158). Coleman has reviewed the literature on the "law of effect" and conducted an experiment showing quite clearly that, at least in rabbit EBCC, the imposition of a contingency between the occurrence of a CR and a reduction in the intensity of a shock US results in less rather than more responding - a finding that completely contradicts a "law of effect" prediction (156). In other experiments, including tail flexion in the rat (159), appetitive jaw movement conditioning in rabbits (160) and human EBCC (157), the lack of significant effect and even inferior conditioning of subjects explicitly designed to benefit from the "law of effect" is clear $(157,159,160)$. In contrast, early experiments by Schlosberg were interpreted as "successful" only if CRs modified the US $(60,161)$. In fact, Schlosberg used the term "adaptive" in describing responses that had an effect on the US and "non-adaptive" for those that did not (p. 383). The pervasiveness of this assumption about the "role" of the occurrence and timing of CRs and its periodic reintroduction (162) may account for more modern EBCC experiments in which responses 
are only considered to be CRs if they occur within an interval that is characterized as "adaptive."

The use of onset latencies to detect adaptively timed CRs and hence, "true CRs" can be traced to another period in the history of EBCC where latencies were used to identify and eliminate the data of "voluntary responders" $(62,163,164)$. Voluntary responders were subjects who were "rejected" from experiments based on the occurrence of short-latency eyeblinks that occurred between 200 and $300 \mathrm{~ms}$ after CS onset and were judged to have the same appearance as subjects who were instructed to blink or by subjects who reported they were blinking "voluntarily" to avoid the air puff (165). This practice has been explicitly adopted by a number of laboratories especially during trace conditioning where there was a long interval between the offset of the CS and the onset of the US because it "corrected for both voluntary and random blinks that could occur as a result of the longer trace intervals" $(166,167)$.

In our view, an empirical approach to determining onset latency needs to be neutral with respect to characterizing responses. We endorse the complete characterization of all responses using a range of dependent variables including onset and peak latency and presenting all response onsets on a latency histogram without any preconceptions of how responses should look or be distributed. Publication of such histograms together with any interpretation of what are considered responses whether they be "adaptive" or not would allow readers to interpret the data for themselves.

\section{SUMMARY AND CONCLUSION}

There is a crucial need to know how responding to stressful events changes as a function of trauma for those who suffer from PTSD. A number of treatment strategies for PTSD are capable of treating only some of the symptoms because the extinction of fear does not deal with the various forms of hyper-vigilance and hyperarousal experienced by people with PTSD, especially in combat veterans. Based on our work on conditioning of the rabbit's NMR, we have developed a preclinical EBCC model of PTSD that addresses both CRs to trauma-associated cues as well as hyperarousal (CRM). Animal models of EBCC are particularly useful here because EBCC is one of the few behavioral paradigms in which there is a one-to-one correspondence between animals and humans. We have demonstrated that CRM follows many of the same behavioral rules as EBCC, can generalize across stimulus modalities, shows sensitivity to context manipulations, and can be exacerbated after an incubation period. Importantly, CRM does not develop in all animals just as PTSD does not develop in all those exposed to trauma, with some individuals demonstrating susceptibility while others show resilience. We have shown that CRs and CRM can be simultaneously extinguished by unpaired stimulus presentations, even when US intensity is reduced to the point where it is barely capable of eliciting a response. This is important because presenting strong unconditioned stimuli as a therapeutic approach would be untenable. These unpaired procedures with attenuated stimuli have direct implications for the treatment of PTSD and could be implemented in a VR environment.

\section{AUTHOR CONTRIBUTIONS}

$\mathrm{BS}$ and LB conceived and wrote the manuscript.

\section{ACKNOWLEDGMENTS}

The authors thank Carrie Smith-Bell for help with data collection and analysis. The work described here was supported by the NIH Intramural program, the Blanchette Rockefeller Neurosciences Institute, and NIH grants MH64715 and MH081159. The contents of this manuscript are solely the responsibility of the authors and do not necessarily represent the official views of the NIMH.

\section{REFERENCES}

1. Breslau N. The epidemiology of posttraumatic stress disorder: what is the extent of the problem? J Clin Psychiatry (2001) 62(Suppl 17):16-22.

2. Difede J, Olden M, Cukor J. Evidence-based treatment of post-traumatic stress disorder. Annu Rev Med (2014) 65:319-32. doi:10.1146/annurev-med051812-145438

3. Morrison FG, Ressler KJ. From the neurobiology of extinction to improved clinical treatments. Depress Anxiety (2014) 31:279-90. doi:10.1002/ da. 22214

4. Creamer M, Elliott P, Forbes D, Biddle D, Hawthorne G. Treatment for combatrelated posttraumatic stress disorder: two-year follow-up. J Trauma Stress (2006) 19:675-85. doi:10.1002/jts.20155

5. Watts BV, Schnurr PP, Mayo L, Young-Xu Y, Weeks WB, Friedman MJ. Metaanalysis of the efficiency of treatments for posttraumatic stress disorder. J Clin Psychiatry (2013) 74:e541-50. doi:10.4088/JCP.12r08225

6. Ramaswamy S, Madaan V, Qadri F, Heaney CJ, North TC, Padala PR, et al. A primary care perspective of posttraumatic stress disorder for the Department of Veterans Affairs. Prim Care Companion J Clin Psychiatry (2005) 7:180-7. doi:10.4088/PCC.v07n0407

7. Rosen CS, Greenbaum MA, Fitt JE, Laffaye C, Norris VA, Kimerling R. Stigma, help-seeking attitudes, and use of psychotherapy in veterans with diagnoses of posttraumatic stress disorder. J Nerv Ment Dis (2011) 199:879-85. doi:10.1097/NMD.0b013e3182349ea5

8. Ramchand R, Schell TL, Karney BR, Osilla KC, Burns RM, Caldarone LB. Disparate prevalence estimates of PTSD among service members who served in Iraq and Afghanistan: possible explanations. J Trauma Stress (2010) 23:59-68. doi: $10.1002 /$ jts. 20486

9. Friedman MJ. Veterans' mental health in the wake of war. N Engl J Med (2005) 352:1287-90. doi:10.1056/NEJMp058028

10. Iversen AC, Van SL, Hughes JH, Greenberg N, Hotopf M, Rona RJ, et al. The stigma of mental health problems and other barriers to care in the UK Armed Forces. BMC Health Serv Res (2011) 1:31. doi:10.1186/1472-6963-11-31

11. Murphy D, Busuttil W. PTSD, stigma and barriers to help-seeking within the UK Armed Forces. J R Army Med Corps (2014). doi:10.1136/jrmac-2014-000344

12. Yaffe K, Vittinghoff E, Lindquist K, Barnes D, Covinsky KE, Neylan T, et al. Posttraumatic stress disorder and risk of dementia among US veterans. Arch Gen Psychiatry (2010) 67:608-13. doi:10.1001/archgenpsychiatry.2010.61

13. Veitch DP, Friedl KE, Weiner MW. Military risk factors for cognitive decline, dementia, and Alzheimer's disease. Curr Alzheimer Res (2013) 10:907-30. doi:10.2174/15672050113109990142

14. Chapman C, Mills K, Slade T, McFarlane AC, Bryant RA, Creamer M, et al. Remission from post-traumatic stress disorder in the general population. Psychol Med (2012) 42:1695-703. doi:10.1017/S0033291711002856

15. Dierperink M, Erbes C, Leskela J, Kaloupek D, Farrer MK, Fisher L, et al. Comparison of treatment for post-traumatic stress disorder among three Department of Veterans Affairs medical centers. Mil Med (2005) 170:305-8.

16. English BA, Jewell M, Jewell G, Ambrose S, Davis LL. Treatment of chronic posttraumatic stress disorder in combat veterans with citalopram. J Clin Psychopharmacol (2006) 26:84-8. doi:10.1097/01.jcp.0000195043.39853.bc

17. Boscarino JA. Posttraumatic stress disorder and mortality among U.S. army veterans 30 years after military service. Ann Epidemiol (2005) 16:248-56. doi:10.1016/j.annepidem.2005.03.009

18. Pompili M, Sher L, Serafini G, Forte A, Innamorati M, Dominici G, et al. Posttraumatic stress disorder and suicide risk among veterans: a literature review. J Nerv Ment Dis (2013) 201:802-12. doi:10.1097/NMD.0b013e3182a21458

19. Sher L, Braquehais MD, Casas M. Posttraumatic stress disorder, depression, and suicide in veteran. Cleve Clin J Med (2012) 79:92-7. doi:10.3949/ccjm.79a. 11069 
20. Yehuda R, Antelman SM. Criteria for rationally evaluating animal models of posttraumatic stress disorder. Biol Psychiatry (1993) 33:479-86. doi:10.1016/ 0006-3223(93)90001-T

21. Cohen H, Zohar J. An animal model of posttraumatic stress disorder. The use of cut-off behavioral criteria. Ann N Y Acad Sci (2004) 1032:167-78. doi:10.1196/annals.1314.014

22. Cohen H, Matar MA, Richter-Levin G, Zohar J. The contribution of an animal model toward uncovering biological risk factors for PTSD. Ann N Y Acad Sci (2006) 1071:335-50. doi:10.1196/annals.1364.026

23. Siegmund A, Wotjak CT. Toward an animal model of posttraumatic stress disorder. Ann N Y Acad Sci (2006) 1071:324-34. doi:10.1196/annals.1364.025

24. Stam R. PTSD and stress sensitization: a tale of brain and body. Part 2: animal models. Neurosci Biobehav Rev (2007) 31:558-84. doi:10.1016/j.neubiorev. 2007.01.001

25. Ursano RJ, Li H, Zhang L, Hough CJ, Fullerton CS, Benedek DM, et al. Models of PTSD and traumatic stress: the importance of research "from bedside to bench to bedside”. Prog Brain Res (2008) 167:203-14. doi:10.1016/S00796123(07)67014-9

26. Yamamoto S, Morinobu S, Takei S, Fuchikami M, Matsuki A, Yamawaki S, et al. Single prolonged stress: toward an animal model of posttraumatic stress disorder. Depress Anxiety (2009) 26:1110-7. doi:10.1002/da.20629

27. Daskalakis NP, Yehuda R, Diamond DM. Animal models in translational studies of PTSD. Psychoneuroendocrinology (2013) 38:1895-911. doi:10.1016/j. psyneuen.2013.06.006

28. Goswami S, Rodriguez-Sierra OE, Cascardi M, Pare D. Animal models of post-traumatic stress disorder: face validity. Front Neurosci (2013) 7:89. doi:10.3389/fnins.2013.00089

29. Matar MA, Zohar J, Cohen H. Translationally relevant modeling of PTSD in rodents. Cell Tissue Res (2013) 354:127-39. doi:10.1007/s00441-013-1687-6

30. Yehuda R, LeDoux J. Response variation following trauma: a translational neuroscience approach to understanding PTSD. Neuron (2007) 56:19-32. doi:10.1016/j.neuron.2007.09.006

31. Johnson LR, McGuire J, Lazarus R, Palmer AA. Pavlovian fear memory circuits and phenotype models of PTSD. Neuropharmacology (2012) 62:638-46. doi:10.1016/j.neuropharm.2011.07.004

32. Radley JJ, Kabbaj M, Jacobson L, Heydendael W, Yehuda R, Herman JP. Stress risk factors and stress-related pathology: neuroplasticity, epigenetics and endophenotypes. Stress (2012) 14:481-97. doi:10.3109/10253890.2011. 604751

33. Lissek S, van Meurs B. Learning models of PTSD: theoretical accounts and psychobiological evidence. Int J Psychophysiol (2014). doi:10.1016/j.ijpsycho. 2014.1011.1006

34. Cohen H, Zohar J, Matar MA, Zeev K, Loewenthal U, Richter-Levin G. Setting apart the affected: the use of behavioral criteria in animal models of post traumatic stress disorder. Neuropsychopharmacology (2004) 29:1962-70. doi:10.1038/sj.npp.1300523

35. Reznikoc R, Diwan M, Nobrega JN, Hamani C. Towards a better preclinical model of PTSD: characterizing animals with weak extinction, maladaptive stress responses and low plasma corticosterone. J Psychiatr Res (2015) 61:158-65. doi:10.1016/j.jpsychires.2014.1012.1017

36. Schreurs BG, Smith-Bell CA, Burhans LB. Unpaired extinction: implications for treating post-traumatic stress disorder. J Psychiatr Res (2011) 45:638-49. doi:10.1016/j.jpsychires.2010.10.010

37. Schreurs BG, Oh MM, Hirashima C, Alkon DL. Conditioning-specific modification of the rabbit's unconditioned nictitating membrane response. Behav Neurosci (1995) 109:24-33. doi:10.1037/0735-7044.109.1.24

38. Schreurs BG, Shi T, Pineda SI, Buck DL. Conditioning the unconditioned response: modification of the rabbit's (Oryctolagus cuniculus) unconditioned nictitating membrane response. J Exp Psychol Anim Behav Process (2000) 26:144-56. doi:10.1037/0097-7403.26.2.144

39. Buck DL, Seager MA, Schreurs BG. Conditioning-specific reflex modification of the rabbit (Oryctolagus cuniculus) nictitating membrane response: generality and nature of the phenomenon. Behav Neurosci (2001) 115:1039-47. doi:10.1037/0735-7044.115.5.1039

40. Schreurs BG. Classical conditioning and modification of the rabbit's (Oryctolagus cuniculus) unconditioned nictitating membrane response. Behav Cogn Neurosci Rev (2003) 2:83-96. doi:10.1177/1534582303002002001

41. Schreurs BG, Gonzalez-Joekes J, Smith-Bell CA. Conditioning-specific reflex modification of the rabbit (Oryctolagus cuniculus) nictitating membrane response is sensitive to context. Learn Behav (2006) 34:315-24. doi:10.3758/ BF03192886

42. Burhans LB, Smith-Bell CA, Schreurs BG. Conditioning-specific reflex modification of the rabbit's nictitating membrane response and heart rate: behavioral rules, neural substrates, and potential applications to post-traumatic stress disorder. Behav Neurosci (2008) 122:1191-206. doi:10.1037/a0013599

43. Smith-Bell CA, Burhans LB, Schreurs BG. Predictors of susceptibility and resilience in an animal model of post traumatic stress disorder. Behav Neurosci (2012) 126:749-61. doi:10.1037/a0030713

44. Gruart A, Yeo CH. Cerebellar cortex and eyeblink conditioning: bilateral regulation of conditioned responses. Exp Brain Res (1995) 104:431-48. doi:10. 1007/BF00231978

45. Wikgren J, Ruusuvirta T, Korhonen T. Reflex facilitation during eyeblink conditioning and subsequent interpositus nucleus inactivation in the rabbit (Oryctolagus cuniculus). Behav Neurosci (2002) 116:1052-8. doi:10.1037/0735-7044. 116.6.1052

46. Servatius RJ, Brennan FX, Beck KD, Beldowicz D, Coyle-Dinorcia K. Stress facilitates acquisition of the classically conditioned eyeblink response at both long and short interstimulus intervals. Learn Motiv (2001) 32:178-92. doi:10.1006/lmot.2000.1071

47. Woodruff-Pak DS, Steinmetz JE. Past, present, and future of human eyeblink conditioning. In: Woodruff-Pak DS, Steinmetz JE, editors. Eyeblink Classical Conditioning Volume 1: Applications in Humans. Boston, MA: Kluwer Academic Publishers (2000). p. 1-17.

48. Gormezano I. Bibliography of human eyeblink conditioning (1899-1985). In: Woodruff-Pak DS, Steinmetz JE, editors. Eyeblink Classical Conditioning Volume 1: Applications in Humans. Boston, MA: Kluwer Academic Publishers (2000). p. 275-307.

49. Cason H. The conditioned eyelid reaction. J Exp Psychol (1922) 5:153-96. doi:10.1037/h0074822

50. Hilgard ER, Marquis DG. Conditioning and Learning. New York, NY: Wiley (1940).

51. Taylor JA. The relationship of anxiety to the conditioned eyelid response. J Exp Psychol (1951) 441:81-92. doi:10.1037/h0059488

52. Spence KW, Taylor JA. The relation of conditioned response strength to anxiety in normal, neurotic, and psychotic subjects. J Exp Psychol (1953) 45:265-72. doi:10.1037/h0056392

53. Taylor JA, Spence KW. Conditioning level in the behavior disorders. J Abnorm Psychol (1954) 49:497-502. doi:10.1037/h0055951

54. Ayers ED, White J, Powell DA. Pavlovian eyeblink conditioning in combat with and without post-traumatic stress disorder. Integr Physiol Behav Sci (2003) 38:230-47. doi:10.1007/BF02688856

55. Burriss L, Ayers E, Powell DA. Combat veterans show normal discrimination during differential trace eyeblink conditioning, but increased responsivity to the conditioned and unconditioned stimulus. JPsychiatr Res (2007) 41:785-94. doi:10.1016/j.jpsychires.2006.04.004

56. Ginsberg JP, Ayers E, Burriss L, Powell DA. Discriminative delay Pavlovian eyeblink conditioning in veterans with and without posttraumatic stress disorder. J Anxiety Disord (2008) 22:809-23. doi:10.1016/j.janxdis.2007.08.009

57. Myers CE, Vanmeenen KM, McAuley JD, Beck KD, Pang KC, Servatius RJ. Behaviorally inhibited temperament is associated with severity of posttraumatic stress disorder symptoms and faster eyeblink conditioning in veterans. Stress (2012) 15:31-44. doi:10.3109/10253890.2011.578184

58. McGlinchey RE, Fortier CB, Venne JR, Maksimovskiy AL, Milberg WP. Effects of OEF/OIF-related physical and emotional co-morbidities on associative learning: concurrent delay and trace eyeblink classical conditioning. Int J Environ Res Public Health (2014) 11:3046-73. doi:10.3390/ijerph110303046

59. Vythulingam M, Lawley M, Collin C, Bonne O, Agarwal R, Hadd K, et al. Hydrocortisone impairs hippocampal-dependent trace eyeblink conditioning in post-traumatic stress disorder. Neuropsychopharmacology (2006) 31:182-8. doi:10.1038/sj.npp.1300843

60. Hughes B, Schlosberg H. Conditioning in the white rat. IV. The conditioned lid reflex. J Exp Psychol (1938) 23:641-50. doi:10.1037/h0059822

61. Gormezano I. Classical conditioning. In: Sidowski JB, editor. Experimental Methods and Instrumentation in Psychology. New York, NY: McGraw-Hill (1966). p. 385-420.

62. Coleman SR, Webster S. The problem of volition and the conditioned reflex. Part II: voluntary-responding subjects, 1951-1980. Behaviorism (1988) 16:17-49. 
63. Gormezano I, Schneiderman N, Deaux EG, Fuentes I. Nictitating membrane: classical conditioning and extinction in the albino rabbit. Science (1962) 138:33-4. doi:10.1126/science.138.3536.33

64. Schneiderman N, Fuentes I, Gormezano I. Acquisition and extinction of the classically conditioned eyelid response in the albino rabbit. Science (1962) 136:650-2. doi:10.1126/science.136.3516.650

65. Deaux EB, Gormezano I. Eyeball retraction: classical conditioning and extinction in the albino rabbit. Science (1963) 141:630-1. doi:10.1126/science.141. 3581.630

66. Gormezano I, Kehoe EJ, Marshall BS. Twenty years of classical conditioning research with the rabbit. 10th ed. In: Sprague JM, editor. Progress in Psychobiology and Physiological Psychology. New York, NY: Academic Press (1983). p. 197-275.

67. Smith MC, Dilollo V, Gormezano I. Conditioned jaw movement in the rabbit. J Comp Physiol Psychol (1966) 62:479-83. doi:10.1037/h0023947

68. Schneiderman N, Smith MC, Smith AC, Gormezano I. Heart rate classical conditioning in rabbits. Psychon Sci (1966) 6:241-2. doi:10.3758/BF03328047

69. Gormezano I. Investigations of defense and reward conditioning in the rabbit. In: Black AH, editor. Classical Conditioning II: Current Research and Theory. New York, NY: Appleton-Century-Crofts (1972). p. 151-81.

70. Berger TW, Alger B, Thompson RF. Neuronal substrate of classical conditioning in the hippocampus. Science (1976) 192:483-5. doi:10.1126/science.1257783

71. Cegavske CF, Thompson RF, Patterson MM, Gormezano I. Mechanisms of efferent neuronal control of the reflex nictitating membrane response in the rabbit. J Comp Physiol Psychol (1976) 90:411-23. doi:10.1037/h0077214

72. Young RA, Cegavske CF, Thompson RF. Tone-induced changes in excitability of abducens motoneurons and of the reflex path of nictitating membrane response in rabbit (Oryctolagus cuniculus). J Comp Physiol Psychol (1976) 90:424-34. doi:10.1037/h0077219

73. Stein L. Habituation and stimulus novelty: a model based on classical conditioning. Psychol Rev (1966) 73:352-6. doi:10.1037/h0023449

74. Thompson RF, Spencer WA. Habituation: a model phenomenon for the study of neuronal substrates of behavior. Psychol Rev (1966) 73:16-43. doi:10.1037/ h0022681

75. Pinsker HM, Kupfermann V, Castellucci VF, Kandel ER. Habituation and dishabituation of the gill-withdrawal reflex in Aplysia. Science (1970) 167:1740-2. doi:10.1126/science.167.3926.1740

76. Wine JJ, Krasne FB, Chen L. Habituation and inhibition of the crayfish lateral giant fiber escape response. J Exp Biol (1975) 62:771-82.

77. Lukowiak K. CNS control of the PNS-mediated gill withdrawal reflex and its habituation. Can J Physiol Pharmacol (1977) 55:1252-62. doi:10.1139/y77-171

78. Boulis NM, Sahley CL. A behavioral analysis of habituation and sensitization of shortening in the semi-intact leech. J Neurosci (1988) 8:4621-7.

79. Tomsic D, Massoni V, Maldonado H. Habituation to a danger stimulus in two semiterrestrial crabs: ontogenic, ecological and opioid modulation correlates. J Comp Physiol A (1993) 173:621-33. doi:10.1007/BF00197770

80. Blumenthal TD. Short lead interval startle modification. In: Dawson ME, Schell AM, Bohmelt AH, editors. Startle Modification: Implications for Neuroscience, Cognitive Science, and Clinical Science. Cambridge: Cambridge University Press (1999). p. 51-71.

81. Humpherys D, Eggan K, Akutsu H, Hochedlinger K, Rideout WM III, Biniszkiewicz D, et al. Epigenetic instability in ES cells and cloned mice. Science (2001) 293:95-7. doi:10.1126/science.1061402

82. Mattingly BA, Koch C, Osborne FH, Gotsick JE. Stimulus and response factors affecting the development of behavioral sensitization to apomorphine. Psychopharmacology (1997) 130:109-16. doi:10.1007/s002130050217

83. Gormezano I, Kehoe EJ. Classical conditioning: some methodologicalconceptual issues. 2nd ed. In: Estes WK, editor. Handbook of Learning and Cognitive Processes. Hillsdale, NJ: Erlbaum (1975). p. 143-79.

84. Ison JR, Leonard DW. Effects of auditory stimuli on the amplitude of the nictitating membrane reflex of the rabbit (Oryctolagus cuniculus). J Comp Physiol Psychol (1971) 75:157-64. doi:10.1037/h0030671

85. Donegan NH. Priming-produced facilitation or diminution of responding to a Pavlovian unconditioned stimulus. J Exp Psychol Anim Behav Process (1981) 7:295-312.

86. Weisz DJ, McInerny J. An associative process maintains reflex facilitation of the unconditioned nictitating membrane response during the early stages of training. Behav Neurosci (1990) 104:21-7. doi:10.1037/0735-7044.104.1.21
87. Weisz DJ, Walts C. Reflex facilitation of the rabbit nictitating membrane response by an auditory stimulus as a function of interstimulus interval. Behav Neurosci (1990) 104:11-20. doi:10.1037/0735-7044.104.1.11

88. Whalen PJ, Kapp BS. Contributions of the amygdaloid central nucleus to the modulation of the nictitating membrane reflex in the rabbit. Behav Neurosci (1991) 105:141-53. doi:10.1037/0735-7044.105.1.141

89. Canli T, Detmer WM, Donegan NH. Potentiation or diminution of discrete motor unconditioned responses (rabbit eyelid) to an aversive Pavlovian unconditioned stimulus by two associative processes: conditioned fear and a conditioned diminution of unconditioned stimulus processing. Behav Neurosci (1992) 106:498-508. doi:10.1037/0735-7044.106.3.498

90. Weisz DJ, Harden DG, Xiang Z. Effects of amygdala lesions on reflex facilitation and conditioned response acquisition during nictitating membrane response conditioning in rabbit. Behav Neurosci (1992) 106:262-73. doi:10.1037/07357044.106.2.262

91. Yang BY, Weisz DJ. An auditory conditioned stimulus modulates unconditioned stimulus-elicited neuronal activity in the cerebellar anterior interpositus and dentate nuclei during nictitating membrane response conditioning in rabbits. Behav Neurosci (1992) 106:889-99. doi:10.1037/0735-7044.106.6.889

92. Flaten MA. A comparison of electromyographic and photoelectric techniques in the study of classical eyeblink conditioning and startle reflex modification. Psychophysiology (1993) 7:230-7.

93. Lam Y-W, Wong A, Canli T, Brown TH. Conditioned enhancement of the early component of the rat eyeblink reflex. Neurobiol Learn Mem (1996) 66:212-20. doi:10.1006/nlme.1996.0061

94. Nowak AJ, Goodell-Marshall B, Kehoe EJ, Gormezano I. Elicitation, modification, and conditioning of the rabbit nictitating membrane response by electrical stimulation in the spinal trigeminal nucleus, inferior olive, interpositus nucleus, and red nucleus. Behav Neurosci (1997) 111:1041-55. doi:10.1037/ 0735-7044.111.5.1041

95. Marcos JL, Redondo J. Effects of conditioned stimulus presentation on diminution of the unconditioned response in aversive classical conditioning. Biol Psychiatry (1999) 50:89-102. doi:10.1016/S0301-0511(99)00007-1

96. Nowak AJ, Kehoe EJ, Macrae M, Gormezano I. Conditioning and reflex modification of the rabbit nictitating membrane response using electrical stimulation in auditory nuclei. Behav Brain Res (1999) 105:189-98. doi:10.1016/S01664328(99)00073-X

97. Alkon DL. Memory storage and neural systems. Sci Am (1989) 261:42-50. doi:10.1038/scientificamerican0789-42

98. Alkon DL, Blackwell KT, Barbour GS, Werness SA, Vogl TP. Biological plausibility of synaptic associative memory models. Neural Netw (1994) 7:1005-17. doi:10.1016/S0893-6080(05)80156-X

99. Schreurs BG, Crum JM, Wang D, Smith-Bell CA. Conditioning-specific reflex modification of rabbit (Oryctolagus cuniculus) heart rate. Behav Neurosci (2005) 119:1484-95. doi:10.1037/0735-7044.119.6.1484

100. Schreurs BG, Smith-Bell CA, Burhans LB. Classical conditioning and conditioning-specific reflex modification of rabbit heart rate as a function of unconditioned stimulus location. Behav Neurosci (2011) 125:604-12. doi: $10.1037 / \mathrm{a} 0024325$

101. Berthier NE. Muscle activity during unconditioned and conditioned eye blinks in the rabbit. Behav Brain Res (1992) 48:21-8. doi:10.1016/S0166-4328(05) 80135-4

102. Smith MC, Coleman SR, Gormezano I. Classical conditioning of the rabbit's nictitating membrane response at backward, simultaneous, and forward CS-US intervals. J Comp Physiol Psychol (1969) 69:226-31. doi:10.1037/h0028212

103. Kehoe EJ, Macrae M. Fundamental behavioral methods and findings in classical conditioning. 1st ed. In: Moore JW, editor. A Neuroscientist's Guide to Classical Conditioning. New York, NY: Springer (2002). p. 171-231.

104. Seager MA, Smith-Bell CA, Schreurs BG. Conditioning-specific reflex modification of the rabbit (Oryctolagus cuniculus) nictitating membrane response: US intensity effects. Learn Behav (2003) 31:292-8. doi:10.3758/ BF03195990

105. Schreurs BG, Smith-Bell CA, Darwish DS, Stankovic G, Sparks DL. High dietary cholesterol facilitates classical conditioning of the rabbit's nictitating membrane response. Nutr Neurosci (2007) 10:31-43. doi:10.1080/ 10284150701565540

106. Hupka RB, Liu SS, Moore JW. Auditory differential conditioning of the rabbit nictitating membrane response: V. Stimulus generalization as a function of the 
position of the CS+ and CS- on the frequency dimension. Psychon Sci (1969) 15:129-31. doi:10.3758/BF03336238

107. Moore JW. Stimulus control: studies in auditory generalization in rabbits. In: Black AH, Prokasy WF, editors. Classical Conditioning II: Current Research and Theory. New York, NY: Appleton-Century-Crofts (1972). p. 206-30.

108. Scavio MJ Jr, Gormezano I. CS intensity effects upon rabbit nictitating membrane conditioning, extinction, and generalization. Pavlov J Biol Sci (1974) 9:25-34.

109. Penick S, Solomon PR. Hippocampus, context, and conditioning. Behav Neurosci (1991) 105:611-7. doi:10.1037/0735-7044.105.5.611

110. Zhou Y, Riccio DC. Manipulation of components of context: the context shift effect and forgetting of stimulus attributes. Learn Motiv (1996) 27:400-7. doi:10.1006/lmot.1996.0023

111. Millin PM, Riccio DC. Is the context shift effect a case of retrieval failure? The effects of retrieval enhancing treatments on forgetting under altered stimulus conditions in rats. J Exp Psychol Anim Behav Process (2004) 30:325-34. doi:10.1037/0097-7403.30.4.325

112. Boakes RA, Westbrook RF, Elliott M, Swinbourne AL. Context dependency of conditioned aversions to water and sweet tastes. J Exp Psychol Anim Behav Process (1997) 23:56-67.

113. Gunther LM, Miller RR, Matute H. CSs and USs: what's the difference? J Exp Psychol Anim Behav Process (1997) 23:15-30.

114. Pole N. The psychophysiology of posttraumatic stress disorder: a meta-analysis. Psychol Bull (2007) 33:725-46. doi:10.1037/0033-2909.133.5.725

115. Hennig-Fast K, Werner NS, Lermer R, Latscha K, Meister F, Reiser M, et al. After facing traumatic stress: brain activation, cognition and stress coping in policemen. J Psychiatr Res (2009) 43:1146-55. doi:10.1016/j.jpsychires.2009.03.001

116. Schumacher S, Schnyder U, Furrer M, Mueller-Pfeiffer C, Wilhelm FH, Moergeli $\mathrm{H}$, et al. Startle reactivity in the long-term after severe accidental injury: preliminary data. Psychiatry Res (2013) 210:570-4. doi:10.1016/j. psychres.2013.06.034

117. Vrana SR, Calhoun PS, McClernon FJ, Dennis MF, Lee ST, Beckham JC. Effects of smoking on the acoustic startle response and prepulse inhibition in smokers with and without posttraumatic stress disorder. Psychopharmacology (2013) 230:477-85. doi:10.1007/s00213-013-3181-y

118. Smid GE, Mooren TT, van der Mast RC, Gersons BP, Kleber RJ. Delayed posttraumatic stress disorder: systematic review, meta-analysis, and metaregression analysis of prospective studies. J Clin Psychiatry (2009) 70:1572-82. doi:10.4088/JCP.08r04484

119. Utzon-Frank N, Breinegaard N, Bertelsen M, Borritz M, Eller NH, Nordentoft $\mathrm{M}$, et al. Occurrence of delayed-onset post-traumatic stress disorder: a systematic review and meta-analysis of prospective studies. Scand J Work Environ Health (2014) 40:215-29. doi:10.5271/sjweh.3420

120. Andrews B, Brewin CR, Philpott R, Stewart L. Delayed-onset posttraumatic stress disorder: a systematic review of the evidence. Am J Psychiatry (2007) 164:1319-26. doi:10.1176/appi.ajp.2007.06091491

121. Frueh BC, Grubaugh AL, Yeager DE, Magruder KM. Delayed-onset posttraumatic stress disorder among war veterans in primary care clinics. $\mathrm{Br} J$ Psychiatry (2009) 194:515-20. doi:10.1192/bjp.bp.108.054700

122. Andrews B, Brewin CR, Stewart L, Philpott R, Hejdenberg J. Comparison of immediate-onset and delayed-onset posttraumatic stress disorder in military veterans. J Abnorm Psychol (2009) 118:767-77. doi:10.1037/a0017203

123. Horesh D, Solomon Z, Zerach G, Ein-Dor T. Delayed-onset PTSD among war veterans: the role of life events throughout the life cycle. Soc Psychiatry Psychiatr Epidemiol (2010) 46:863-70. doi:10.1007/s00127-010-0255-6

124. Fikretoglu D, Liu A. Prevalence, correlates, and clincial features of delayed-onset posttraumatic stress disorder in a nationally representative military sample. Soc Psychiatry Psychiatr Epidemiol (2012) 47:1359-66. doi:10.1007/s00127-0110444-y

125. Hauger RL, Olivares-Reyes JA, Dautzenberg FM, Lohr JB, Braun S, Oakley RH. Molecular and cell signaling targets for PTSD pathophysiology and pharmacotherapy. Neuropharmacology (2012) 62:705-14. doi:10.1016/j.neuropharm. 2011.11.007

126. Schreurs BG, Smith-Bell CA, Burhans LB. Incubation of conditioning-specific reflex modification: implications for post traumatic stress disorder. J Psychiatr Res (2011) 45:1535-41. doi:10.1016/j.jpsychires.2011.07.003

127. Bouton ME, Westbrook RF, Corcoran KA, Maren S. Contextual and temporal modulation of extinction: behavioral and biological mechanisms. Biol Psychiatry (2006) 60:352-60. doi:10.1016/j.biopsych.2005.12.015
128. Milad MR, Rauch SL, Pitman RK, Quirk GJ. Fear extinction in rats: implications for human brain imaging and anxiety disorders. Biol Psychiatry (2006) 73:61-71. doi:10.1016/j.biopsycho.2006.01.008

129. Pitman RK, Orr SP, Shalev AY. Once bitten, twice shy: beyond the conditioning model of PTSD. Biol Psychiatry (1993) 33:145-6. doi:10.1016/0006-3223(93) 90132-W

130. Brewin CR, Holmes EA. Psychological theories of posttraumatic stress disorder. Clin Psychol Rev (2003) 23:339-76. doi:10.1016/S0272-7358(03)00033-3

131. Rauch SL, Shin LM, Phelps EA. Neurocircuitry models of posttraumatic stress disorder and extinction: human neuroimaging research - past, present, and future. Biol Psychiatry (2006) 60:376-82. doi:10.1016/j.biopsych.2006.06.004

132. McNally RJ. Mechanisms of exposure therapy: how neuroscience can improve psychological treatments for anxiety disorders. Clin Psychol Rev (2007) 27:750-9. doi:10.1016/j.cpr.2007.01.003

133. Maren S. Seeking a spotless mind: extinction, deconsolidation, and erasure of fear memory. Neuron (2011) 70:830-45. doi:10.1016/j.neuron.2011.04.023

134. Milad MR, Quirk GJ. Fear extinction as a model for translational neuroscience: ten years of progress. Annu Rev Psychol (2012) 63:129-51. doi:10.1146/annurev. psych.121208.131631

135. Parsons RG, Ressler KJ. Implications of memory modulation for posttraumatic stress and fear disorders. Nat Neurosci (2013) 16:146-53. doi:10. 1038/nn.3296

136. Briscione MA, Jovanovic T, Norrholm SD. Conditioned fear associated phenotypes as robust, translational indices of trauma-, stressor-, and anxiety-related behaviors. Front Psychiatry (2014) 5:88. doi:10.3389/fpsyt.2014.00088

137. VanElzakker MB, Dahlgren MK, Davis FC, Dubois S, Shin LM. From Pavlov to PTSD: the extinction of conditioned fear in rodents, humans, and anxiety disorders. Neurobiol Learn Mem (2014) 113:3-18. doi:10.1016/j.nlm.2013.11.014

138. Rauhut AS, Thomas BL, Ayres JJ. Treatments that weaken Pavlovian conditioned fear and thwart its renewal in rats: implications for treating human phobias. J Exp Psychol Anim Behav Process (2001) 27:99-114. doi:10.1037/ 0097-7403.27.2.99

139. Thomas BL, Longo CL, Ayres JJ. Thwarting the renewal (relapse) of conditioned fear with the explicitly unpaired procedure: possible interpretations and implications for treating human fears and phobias. Learn Motiv (2005) 36:374-407. doi:10.1016/j.lmot.2004.11.005

140. Vervleit B, Vansteenwegen D, Hermans D. Unpaired shocks during extinction weaken the contextual renewal of a conditioned discrimination. Learn Motiv (2010) 41:22-31. doi:10.1016/j.lmot.2009.08.001

141. Spence KW. Extinction of the human eyelid CR as a function of presence or absence of the UCS during extinction. J Exp Psychol (1966) 71:642-8. doi:10.1037/h0023108

142. Leonard DW. Partial reinforcement effects in classical conditioning in rabbits and human beings. J Comp Physiol Psychol (1975) 88:596-608. doi:10.1037/ h0076419

143. Frey PW, Butler CS. Extinction after aversive conditioning: an associative or nonassociative process? Learn Motiv (1977) 8:1-17. doi:10.1016/00239690(77)90063-7

144. Kehoe EJ, Weidemann G, Dartnall S. Apparatus exposure produces profound declines in conditioned nictitating-membrane responses to discrete conditioned stimuli by the rabbit. J Exp Psychol Anim Behav Process (2004) 30:259-70. doi:10.1037/0097-7403.30.4.259

145. Rothbaum BO, Hodges LF, Ready D, Graap K, Alarcon RD. Virtual reality exposure therapy for Vietnam veterans with posttraumatic stress disorder. J Clin Psychiatry (2001) 62:617-22. doi:10.4088/JCP.v62n0808

146. Beck JG, Palyo SA, Winer EH, Schwagler BE, Ang EJ. Virtual reality exposure therapy for PTSD symptoms after a road accident: an uncontrolled case series. Behav Ther (2007) 38:39-48. doi:10.1016/j.beth.2006.04.001

147. Difede J, Cukor J, Jayasubghe N, Patt I, Jedel S, Spielman L, et al. Virtual reality exposure therapy for the treatment of posttraumatic stress disorder following September 11, 2001. J Clin Psychiatry (2007) 68:1639-47. doi:10.4088/JCP.v68n1102

148. Gerardi M, Cukor J, Difede J, Rizzo A, Rothbaum BO. Virtual reality exposure therapy for post-traumatic stress disorder and other anxiety disorders. Curr Psychiatry Rep (2010) 12:298-305. doi:10.1007/s11920-010-0128-4

149. Reger GM, Holloway KM, Candy C, Rothbaum BO, Difede J, Rizzo AA, et al. Effectiveness of virtual reality exposure therapy for active duty soldiers in a military mental health clinic. J Trauma Stress (2011) 24:93-6. doi:10.1002/ jts. 20574 
150. McLay RN, Graap K, Spira J, Perlman K, Johnston S, Rothbaum BO, et al. Development and testing of virtual reality exposure therapy for post-traumatic stress disorder in active duty service members who served in Iraq and Afghanistan. Mil Med (2012) 177:635-42. doi:10.7205/MILMED-D-11-00221

151. Motraghi TE, Seim RW, Meyer EC, Morisette SB. Virtual reality exposure therapy for the treatment of posttraumatic stress disorder: a methodological review using CONSORT guidelines. J Clin Psychol (2014) 70:197-208. doi:10.1002/jclp.22051

152. Gormezano I, Gibbs CM. Transduction of the rabbit's nictitating membrane response. Behav Res Methods Instrum Comput (1988) 20:18-21. doi:10.3758/ BF03202596

153. Marshall-Goodell B, Schreurs BG, Gormezano I. Ruler vs. the Apple II/FIRST system analysis of analog signals in classical conditioning. Behav Res Methods Instrum (1982) 14:519-25. doi:10.3758/BF03203415

154. Garcia KS, Mauk MD, Weidemann G, Kehoe EJ. Covariation of alternative measures of responding in rabbit (Oryctolagus cuniculus) eyeblink conditioning during acquisition training and tone generalization. Behav Neurosci (2003) 117:292-303. doi:10.1037/0735-7044.117.2.292

155. Burhans LB, Schreurs BG. Inactivation of the central nucleus of the amygdala abolishes conditioning-specific reflex modification of the rabbit nictitating membrane response and delays classical conditioning. Behav Neurosci (2008) 122:75-88. doi:10.1037/0735-7044.122.1.75

156. Coleman SR. Consequences of response-contingent change in unconditioned stimulus intensity upon the rabbit (Oryctolagus cuniculus) nictitating membrane response. JComp Physiol Psychol (1975) 88:591-5. doi:10.1037/h0076413

157. Clark CG, Prokasy WF. Manipulation of response-contingent unconditionedstimulus intensity in human eyelid conditioning: a two-phase model analysis. Mem Cognit (1976) 4:277-82. doi:10.3758/BF03213176

158. Coleman SR, Gormezano I. Classical conditioning and the "law of effect": historical and empirical assessment. Behaviorism (1979) 7:1-33.

159. Miller RR, Greco C, Vigorito M. Classically conditioned tail flexion in rats: CRcontingent modification of US intensity as a test of the preparatory response hypothesis. Anim Learn Behav (1981) 9:80-8. doi:10.3758/BF03212029

160. Gormezano I, Coleman SR. The law of effect and CR contingency modification of the UCS. Cond Reflex (1973) 8:41-56.

161. Schlosberg H. The relationship between success and the laws of conditioning. Psychol Rev (1937) 44:379-94. doi:10.1037/h0062249
162. Perkins CC Jr. An analysis of the concept of reinforcement. Psychol Rev (1968) 75:155-72. doi:10.1037/h0025509

163. Gormezano I. Yoked comparisons of classical and instrumental conditioning of the eyelid response; and an addendum on "voluntary responders". In: Prokasy WF, editor. Classical Conditioning. New York, NY: Appleton-Century-Crofts (1965). p. 48-70.

164. Coleman SR. The problem of volition and the conditioned reflex. Part I: conceptual background, 1900-1940. Behaviorism (1985) 13:99-124.

165. Spence KW, Ross LE. A methodological study of the form and latency of eyelid response in conditioning. J Exp Psychol (1959) 58:376-81. doi:10.1523/ JNEUROSCI.2455-10.2010

166. Finkbiner RG, Woodruff-Pak DS. Classical eyeblink conditioning in adulthood: effects of age and interstimulus interval on acquisition in the trace paradigm. Psychol Aging (1991) 6:109-17. doi:10.1037/0882-7974.6.1.109

167. Solomon PR, Blanchard S, Levine E, Velazquez E, Groccia-Ellison ME. Attenuation of age-related conditioning deficits in humans by extension of the interstimulus interval. Psychol Aging (1991) 6:36-42. doi:10.1037/0882-7974. 6.1 .36

Conflict of Interest Statement: The authors declare that the research was conducted in the absence of any commercial or financial relationships that could be construed as a potential conflict of interest.

Received: 09 February 2015; paper pending published: 03 March 2015; accepted: 25 March 2015; published online: 08 April 2015.

Citation: Schreurs BG and Burhans LB (2015) Eyeblink classical conditioning and post-traumatic stress disorder - a model systems approach. Front. Psychiatry 6:50. doi: 10.3389/fpsyt.2015.00050

This article was submitted to Systems Biology, a section of the journal Frontiers in Psychiatry.

Copyright (C) 2015 Schreurs and Burhans. This is an open-access article distributed under the terms of the Creative Commons Attribution License (CC BY). The use, distribution or reproduction in other forums is permitted, provided the original author(s) or licensor are credited and that the original publication in this journal is cited, in accordance with accepted academic practice. No use, distribution or reproduction is permitted which does not comply with these terms. 